\title{
Radical Copolymerization of Vinyl Ketones. I. Copolymerization with Acrylonitrile
}

\author{
José Luis Acosta, Roberto SAstre, Mercedes Garcia, \\ and José FonTÁN \\ Instituto de Plásticos y Caucho, Juan de la Cierva, 3 \\ Madrid-6, Spain.
}

(Received January 27, 1975)

\begin{abstract}
A series of copolymers of acrylonitrile with various vinyl ketones were prepared via radical polymerization as models of photodegradable polymers. The kinetics of the copolymerization was studied and the correlation between the reactivity of vinyl ketones and polar, steric and resonance effects of substituents was established on the basis of the Taft equation.

The reactivity of the studied vinyl ketonic monomers appeared to depend on the polar nature of the substituent but it was not affected by the steric nature.

KEY WORDS Radical Copolymerization / Acrylonitrile / Vinyl

Ketone Copolymers / Kinetic / Substituent Effects /
\end{abstract}

The problem of solid waste disposal has led to numerous investigations of polymer degradation as a way for destroying polymeric wastes. Some authors have reported polymeric materials that undergo accelerated photodegradation in the presence of sunlight, due to photosensitizing groups introduced into the structure of polymer molecules during the synthesis process.

Deliberate introduction of carbonyl groups into a polymeric chain can therefore be used to sensitize the polymer breakdown by UV light: An example of this, as reported by Guillet and coworkers $^{1-3}$ and Kato and Yoneshige, ${ }^{4}$ is the photolysis of copolymers of unsaturated ketones with several vinyl monomers.

In spite of the great importance of vinyl ketone copolymers as new controlled photodegradable materials, only the copolymerization of some vinyl ketones as described by Lyons, ${ }^{5}$ have been studied so far.

The present paper describes the reactivities of a series of vinyl ketones and their correlation with the substituent effect on the free-radical copolymerization with acrilonitrile as a reference monomer.

\section{EXPERIMENTAL}

\section{Materials}

$t$-Butyl vinyl ketone was prepared by Cologne $\operatorname{method}^{6}$ from the pinacolin, which is in turn obtained from pinacol prepared by pinacolin transposition of acetone reduction. ${ }^{7}$ Phenyl vinyl ketone, isopropyl vinyl ketone, and ethyl vinyl ketone were obtained by treating the appropriate aryl chloride in methylene chloride solutton with ethylene and aluminium chloride. ${ }^{8}$

Acrylonitrile (AN) and dimethylsulfoxide (DMSO) or dimethylformamide (DMF) were purified by fractionated distillation from the commercial products and azobisisobutyronitrile (AIBN) by consecutive recrystallization in chloroform-methanol.

\section{Copolymerization}

Polymeric reactions were carried out in Pyrex tubes. Once they were charged with the monomers, solvent and initiator (all of them freshly purified) were degassed on the vacuum line by three freeze-thaw cycles, and then sealed and immediately sunk in a thermostat at the previously fixed temperature. Once the reaction time is over, the tubes were withdrawn, cooled quickly and opened.

The reaction product obtained was poured into water or dimethyl ether; the precipitate was carefully filtered, dried and weighted. Every obtained polymer was purified by repeated dissolution and precipitation in the system DMSOwater or dimethyl ether they were dried at 
reduced pressure and $45^{\circ} \mathrm{C}$ in the dark.

Analysis

The composition of samples was determined from the nitogen content using an automatic analyzer.

The intrinsic viscosities were determined at $30^{\circ} \mathrm{C}$ with solutions of DMF using a Ubbleholde viscometer.

Reactivity ratios of the monomers were cal- culated from the copolymer composition using the Finemman-Ross $\operatorname{method}^{9}$ and the $Q-e$ according parameters were determined to the Alfrey_-Price method. ${ }^{10}$

\section{RESULTS AND DISCUSSION}

The conditions and results of the copolymerization in DMSO or DMF solution of acrylonitrile $\left(M_{1}\right)$ and various vinyl ketones $\left(M_{2}\right)$ at

Table I. Copolymerization of acrylonitrile $\left(\mathrm{M}_{1}\right)-t$-butyl vinyl ketone $\left(\mathrm{M}_{2}\right)$ in $\mathrm{DMF}^{\mathrm{a}}$

\begin{tabular}{ccccccc}
\hline No. & $\begin{array}{c}\text { AN in } \\
\text { comonomer } \\
F_{1} \mathrm{~b}\end{array}$ & $\begin{array}{c}\text { Time, } \\
\min \end{array}$ & $\begin{array}{c}\text { Conversion, } \\
\%\end{array}$ & $\begin{array}{c}\text { AN in co- } \\
\text { polymer, } \\
f_{\mathrm{b}} \mathrm{b}\end{array}$ & $\begin{array}{c}{[\eta],} \\
\mathrm{d} l / \mathrm{g}\end{array}$ & $\begin{array}{c}\text { Copolymn rate, } \\
\mathrm{mol}^{-1} \mathrm{~min}^{-1}\end{array}$ \\
\hline 1 & 1.000 & - & - & - & 2.01 & - \\
2 & 0.936 & 8 & 4.48 & 0.890 & - & 0.878 \\
3 & 0.862 & 8 & 4.79 & 0.766 & 1.94 & 0.883 \\
4 & 0.776 & 7 & 5.27 & 0.646 & - & 0.893 \\
5 & 0.716 & 7 & 9.41 & 0.615 & 1.80 & 0.902 \\
6 & 0.000 & - & - & - & 1.08 & - \\
\hline
\end{tabular}

- Temp, $60^{\circ} \mathrm{C} ;\left[\mathrm{M}_{1}\right]+\left[\mathrm{M}_{2}\right], 7.21 \mathrm{~mol} / l ;[\mathrm{AIBN}], 0.0204 \mathrm{~mol} / l$.

b $F_{1}$ and $f_{1}$ are the mole fractions of $\mathrm{AN}$ in monomer mixture and in copolymers, respectively.

Table II. Copolymerization of acrylonitrile $\left(\mathrm{M}_{1}\right)$ - phenyl vinyl ketone $\left(\mathrm{M}_{2}\right)$ in $\mathrm{DMF}^{\mathrm{a}}$

\begin{tabular}{ccccccc}
\hline No. & $\begin{array}{c}\text { AN in } \\
\text { comonomer, } \\
F_{1}{ }^{\mathrm{b}}\end{array}$ & $\begin{array}{c}\text { Time, } \\
\text { min }\end{array}$ & $\begin{array}{c}\text { Conversion, } \\
\%\end{array}$ & $\begin{array}{c}\text { AN in co- } \\
\text { polymer, } \\
f_{1}^{\mathrm{b}}\end{array}$ & $\begin{array}{c}{[\eta],} \\
\mathrm{d} l / \mathrm{g}\end{array}$ & $\begin{array}{c}\text { Copolymn rate, } \\
\mathrm{mol}^{-1} \mathrm{~min}^{-1}\end{array}$ \\
\hline 1 & 1.000 & - & - & 1.000 & 2.01 & - \\
2 & 0.945 & 15 & 6.41 & 0.793 & 1.19 & 0.449 \\
3 & 0.945 & 15 & 6.44 & 0.779 & - & 0.449 \\
4 & 0.900 & 15 & 6.01 & 0.690 & 1.18 & 0.447 \\
5 & 0.816 & 16 & 1.96 & 0.574 & - & 0.441 \\
6 & 0.655 & 25 & 6.86 & 0.393 & 0.425 & 0.268 \\
7 & 0.558 & 35 & 8.94 & 0.307 & - & - \\
8 & 0.000 & - & - & 0.000 & - & - \\
\hline
\end{tabular}

a Temp, $60^{\circ} \mathrm{C} ;\left[\mathrm{M}_{1}\right]+\left[\mathrm{M}_{2}\right], 7.20 \mathrm{~mol} / l ;$ [AIBN], $0.0204 \mathrm{~mol} / l$.

b $F_{1}$ and $f_{1}$ are the mole fractions of $\mathrm{AN}$ in monomer mixture and in copolymer, respectively.

Table III. Copolymerization of acrylonitrile $\left(\mathrm{M}_{1}\right)$-ethyl vinyl ketone $\left(\mathrm{M}_{2}\right)$ in DMSO ${ }^{\mathrm{a}}$

\begin{tabular}{|c|c|c|c|c|c|c|}
\hline No. & $\begin{array}{c}\mathrm{AN} \text { in } \\
\text { comonomer, } \\
F_{1}{ }^{\mathrm{b}}\end{array}$ & $\begin{array}{l}\text { Time, } \\
\text { min }\end{array}$ & $\begin{array}{c}\text { Conversion, } \\
\%\end{array}$ & $\begin{array}{c}\text { AN in co- } \\
\text { ploymer, } \\
f_{1}{ }^{b}\end{array}$ & $\begin{array}{l}{[\eta]} \\
\mathrm{d} l / \mathrm{g}\end{array}$ & $\begin{array}{l}\text { Copolymn rate, } \\
\text { mol } l^{-1} \mathrm{~min}^{-1}\end{array}$ \\
\hline 1 & 1.000 & - & - & 1.000 & 2.01 & - \\
\hline 2 & 0.931 & 21 & 5.46 & 0.865 & 1.83 & 0.331 \\
\hline 3 & 0.735 & 17 & 7.36 & 0.610 & - & 0.400 \\
\hline 4 & 0.601 & 14 & 5.91 & 0.465 & - & 0.494 \\
\hline 5 & 0.392 & 12 & 6.88 & 0.260 & - & 0.570 \\
\hline 6 & 0.143 & 10 & 4.35 & 0.150 & 1.23 & 0.703 \\
\hline 7 & 0.000 & - & - & 0.000 & 1.43 & - \\
\hline
\end{tabular}

a Temp, $60^{\circ} \mathrm{C},\left[\mathrm{M}_{1}\right]+\left[\mathrm{M}_{2}\right], 7.35 \mathrm{~mol} / l ;$ [AIBN], $0.0204 \mathrm{~mol} / l$.

b $F_{1}$ and $f_{1}$ are the mole fractions of $\mathrm{AN}$ in monomer mixture and in copolymer, respectively. 
Table IV. Copolymerization of acrylonitrile $\left(\mathrm{M}_{1}\right)$ - isopropyl vinyl ketone $\left(\mathrm{M}_{2}\right)$ in $\mathrm{DMSO}^{\mathrm{a}}$

\begin{tabular}{ccccccc}
\hline No. & $\begin{array}{c}\text { AN in } \\
\text { comonomer, } \\
F_{1} \mathrm{~b}\end{array}$ & $\begin{array}{c}\text { Time, } \\
\mathrm{min}\end{array}$ & $\begin{array}{c}\text { Conversion, } \\
\%\end{array}$ & $\begin{array}{c}\text { AN in co- } \\
\text { polymer, } \\
f_{1} \mathrm{~b}\end{array}$ & $\begin{array}{c}{[\eta],} \\
\mathrm{d} l / \mathrm{g}\end{array}$ & $\begin{array}{c}\text { Copolymn rate, } \\
\mathrm{mol}^{-1} \mathrm{~min}^{-1}\end{array}$ \\
\hline 1 & 1.000 & - & - & 1.000 & 2.01 & - \\
2 & 0.844 & 21 & 13.51 & 0.690 & 1.16 & 0.247 \\
3 & 0.751 & 20 & 9.36 & 0.565 & - & 0.272 \\
4 & 0.643 & 20 & 9.32 & 0.445 & - & 0.272 \\
5 & 0.520 & 20 & 9.67 & 0.340 & - & 0.271 \\
6 & 0.376 & 20 & 7.85 & 0.210 & 0.60 & 0.277 \\
7 & 0.000 & - & - & 0.000 & 0.84 & - \\
\hline
\end{tabular}

a Temp, $60^{\circ} \mathrm{C} ;\left[\mathrm{M}_{1}\right]+\left[\mathrm{M}_{2}\right.$ ] $6.00 \mathrm{~mol} / l ;$ [AIBN], $0.0204 \mathrm{~mol} / l$.

b $F_{1}$ and $f_{1}$ are the mole fractions of $\mathrm{AN}$ in monomer mixture and in copolymer, respectively.

Table V. Copolymerization parameters of vinyl ketones $\left(\mathrm{M}_{2}\right)$ in their radical copolymerization with acrylonitrile $\left(\mathrm{M}_{1}\right)^{\mathrm{a}}$

\begin{tabular}{lccccccc}
\hline \multicolumn{1}{c}{$\mathrm{R}^{\mathrm{b}}$} & $r_{1}$ & $r_{2}$ & $\log 1 / r_{1}$ & $Q_{2}$ & $e_{2}$ & $\sigma^{*}$ of $\mathrm{R}$ & $\log 1 / r_{1}-0.57 \sigma^{*}$ \\
\hline $\mathrm{CH}_{3}{ }^{\mathrm{e}}$ & $0.61 \pm 0.04$ & $1.78 \pm 0.22$ & 0.215 & 0.69 & 0.68 & -0.18 & 0.318 \\
$\mathrm{C}_{2} \mathrm{H}_{5}$ & $0.44 \pm 0.03$ & $1.30 \pm 0.05$ & 0.357 & 0.53 & 0.42 & -0.10 & 0.414 \\
$i-\mathrm{C}_{3} \mathrm{H}_{7}$ & $0.37 \pm 0.02$ & $1.90 \pm 0.06$ & 0.432 & 0.79 & 0.60 & - & - \\
$t-\mathrm{C}_{4} \mathrm{H}_{9}$ & $0.55 \pm 0.03$ & $1.75 \pm 0.17$ & 0.255 & 0.86 & 1.00 & -0.30 & 0.364 \\
$\mathrm{C}_{6} \mathrm{H}_{5}$ & $0.18 \pm 0.04$ & $1.88 \pm 0.10$ & 0.744 & 0.96 & 0.14 & 0.60 & 0.379 \\
$\mathrm{H}^{\mathrm{d}}$ & $0.42 \pm 0.02$ & $1.60 \pm 0.04$ & 0.380 & 0.85 & 0.73 & 0.00 & 0.380 \\
\hline
\end{tabular}

a Temp, $60^{\circ} \mathrm{C}$.

b Aliphatic or aromatic residue in vinyl ketonic monomer; $\mathrm{CH}_{2}=\mathrm{CH}-\mathrm{CO}-\mathrm{R}$.

c Ref 11.

${ }^{d}$ Ref 12.

$60^{\circ} \mathrm{C}$, are summarized in Tables I-IV.

As shown, in these tables, the higher the vinyl ketone concentration in the reaction medium, the lower the intrinsic viscosity for a definite family, which is a reliable proof of chain transfer to the ketonic comonomer; from the comparison of the viscosity values it follows that, for a given vinyl ketone content in the copolymer the intrinsic viscosity decreases with the increasing hydrogen lability in the vinyl ketone; the isopropyl vinyl ketone gives rise indeed to the higher chain transfer due to its very labile hydrogen atom attached to a tertiary carbon while the lower chain transfer occurs with the $t$-butyl vinyl ketone whose aliphatic residue does not contain any labile hydrogen atom.

As to overall copolymerization rate, the data in Tables I-IV show that for each copolymer family, the higher the vinyl ketone concentration in the feed, the higher the copolymerization rate. On the other hand, for a given concentration of vinyl ketone in feed, the copolymerization rate appeared to increase according to the following order: $t$-butyl, phenyl ethyl, and isopropyl vinyl ketone, inversely to what happens for the chain transfer.

It is clear that such a different vinyl ketones behavior in their copolymerization with acrylonitrile is mainly due to structural factors such as polar resonance and steric effects. These effects are dealt with the following discussion.

The vinyl ketones, studied in this work, differ only with the aliphatic or aromatic residue attached to the carbonyl group; therefore, the influence that these residues may have on both the double bond and the structure of vinyl ketone is expected to condition either the behavior or the reactivity of vinyl ketone in the copolymer reactions.

Firstly, the monomer reactivity is given by reactivity ratios, which in this work have been calculated from the data of Tables I-IV using the Fineman-Ross method; these values are summarized for each pair of monomers in Table 
$V$; in the same way, the factors $Q$ and $e$ were calculated by applying the Alfrey-Price scheme.

From the above mentioned values we can point out as a general rule that vinyl ketone radicals react much more fast with the monomer of their own structure than with the acrylonitrile $\left(k_{11}<k_{12}\right.$ and $\left.k_{22}>k_{21}\right) ; k_{22}$ appeared indeed to increase in proportion as the electron-attracting nature of the substituent increases.

In order to investigate the effect of the substituent on the relative reactivity of a monomer in its reaction with another monomer radical, it has been generally used the Hammett equation; nevertheless in our case, due to the impossibility to evaluate, with this equation, the partial contributions of the polar, resonance and steric effects, we propose the Taft equation ${ }^{13}$ which allows us to evaluate quantitatively the effect of the substituent in radical reactions.

As shown in Table $\mathrm{V}$, the factor $Q$ remains practically constant; we therefore conclude the monomer reactivity to be independent of $Q$ parameter. As a result of this, the above-mentioned Taft equation may be reduced to

$$
\log 1 / r_{1}=\rho^{*} \sigma^{*}+\delta E_{\mathrm{s}}
$$

where $\sigma^{*}$ and $E_{\mathrm{s}}$ are polar and steric substituent constants, and $\rho^{*}$ and $\delta$ are reaction constants, ${ }^{13,15,16}$ respectively.

For a reaction in which the steric effect due to the substituents is not important, i.e., $\delta \simeq 0$, eq 1 becomes identical with the ordinary Hammet equation.

For the purpose of evaluating the polar and steric effects of substituent of vinyl ketones on the copolymerization with acrylonitrile, $\log 1 / r_{1}$

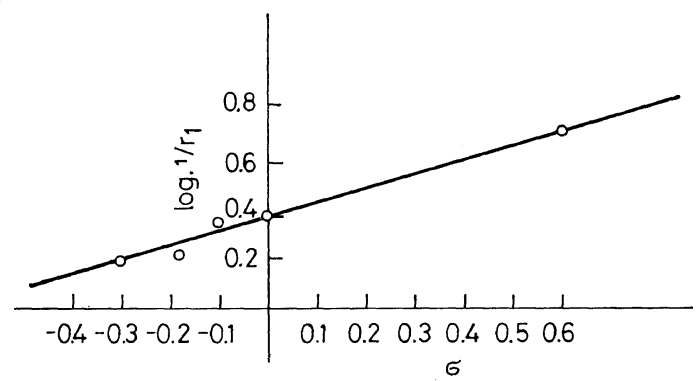

Figure 1. Relationship between relative reactivities $\left(1 / r_{1}\right)$ and the constants of the $R$ groups in vinyl ketones.

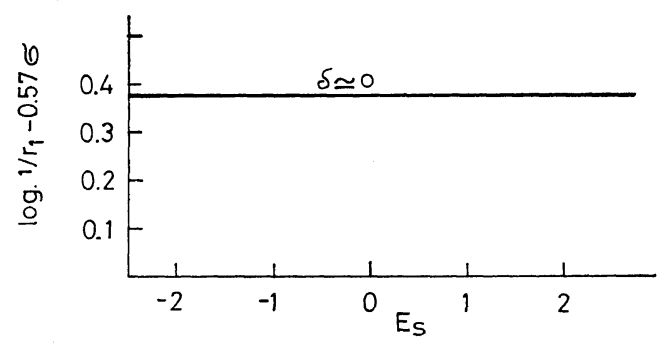

Figure 2. Plots of $\log \left(1 / r_{1}\right)-0.57$ with $E_{\mathrm{s}}$ constant of the $\mathrm{R}$ groups in vinyl ketones.

was plotted against the $\sigma^{*}$ constant $^{14}$ of the corresponding aliphatic or aromatic residue (Figure 1).

This figure shows a fairly good linear relationship from the slope of which a value of 0.57 was obtained for $\rho^{*}$.

Accordingly, it was clear that the reactivities of vinyl ketones towards the polyacrylonitrile radical increased slightly as the electron-withdrawing nature of the substituent increased. When $\log 1 / r_{1}-0.57 \sigma^{*}$ was also plotted against $E_{\mathrm{s}}$ from eq 1 (Figure 2), a straight line with $\delta=0$ was obtained.

It was emphasized from the results of Figures 1 and 2 that the relative reactivities of vinyl ketones monomers towards a radical were dependent on the polar nature of the substituent, not on their steric nature.

\section{REFERENCES}

1. Y. Amerik and J. E. Guillet, Macromolecules, 4, 375 (1971).

2. F. J. Golemba and J. E. Guillet, ibid., 5, 212 (1972).

3. E. Dan and J. E. Guillet, ibid., 6, 231 (1973).

4. M. Kato and Y. Yonshige, Makromol. Chem. 164, 159 (1973).

5. A. R. Lyons, J. Polym. Sci., Part D, 6, 251, (1972).

6. J. Cologne, Bull. Soc. Chim., 2116 (1936).

7. G. Vollon, R. Dulou, and N. Lozac, "Manipulations de Chimie Organique et Cte," Paris, 1946, pp 8-13.

8) P. R. Thomas, G. J. Tyler, T.E. Edwards, A. T. Radcliffe, and R.C.P. Cubbon, Polymer, 5, 525 (1964).

9) M. Fineman and S. D. Ross, J. Polym. Sci., 5, 259 (1950).

10) T. Alfrey, Jr. and C. C. Price, ibid., 2, 101 (1947). 


\section{J. L. Acosta, R. Sastre, M. Garcia, and J. Fontán}

11) F. M. Lewis, C. Walling, W. Cummings, E. R. Briggs, and F. R. Mayo, J. Amer. Chem. Soc., 70, 1527 (1948).

12) W. Kern, University of Mainz, Germany, private communication.

13) K. Hayashi and T. Otsu, Makromol. Chem., 127, 54 (1969).
14) R. W. Taft, in "Steric Effect in Organic Chemistry." Ed. by M.S. Newman, John Wiley \& Sons, Inc., New York, N.Y., 1956, p 556.

15. T. Yamamoto and T. Otsu, Chem. Ind. (London), 787, (1967).

16) T. Yamamoto and T. Otsu, J. Polym. Sci., Part A-1, 7, 1279 (1969). 